\title{
Regulation of expression of the Lactococcus lactis subsp. lactis biovar diacetylactis citrate transport system
}

\author{
Paloma López ${ }^{\text {a* }}$, Djamel Drider ${ }^{\text {a }}$, Nièves García-Quintans ${ }^{\text {a }}$, \\ Maria Angeles Corrales a , Christian Magni ${ }^{\mathrm{b}}$, Mauricio Martín ${ }^{\mathrm{b}}$, \\ Diego de Mendoza ${ }^{b}$
}
${ }^{a}$ Centro de Investigaciones Biológicas (C.S.I.C.), Velázquez. 144, 28006 Madrid, Spain
${ }^{b}$ Programa Multidisciplinario de Biología Experimental (Promubie, Conicet) and
Departamento de Microbiología, Facultad de Ciencias Bioquímicas y Farmaceúticas, Universidad Nacional de Rosario, Suipacha 531, 2000 Rosario, Argentina

\begin{abstract}
Citrate metabolism performed by a number of lactic acid bacteria yields volatile compounds, such as diacetyl and acetaldehyde, which are important for flavour development in fermented milk products. Citrate uptake in Lactococcus lactis subsp. lactis biovar diacetylactis and Leuconostoc mesenteroides subsp. mesenteroides is catalyzed by a secondary carrier, the citrate permease $\mathrm{P}$ (CitP). The presence of $\mathrm{CitP}$ is essential for citrate utilization, since in its absence no citrate metabolism is observed although all enzymes involved in conversion of citrate are present inside the cells. In this review the genetic organization of the plasmid encoding the citrate transport system of lactococci is described, the posttranscriptional regulation of the citQRP operon is presented and the influence of external $\mathrm{pH}$ on citP transcription, citrate uptake and cometabolism of citrate and glucose is discussed. These last studies reveal a novel molecular mechanism that improves the adaptation of $L$, diacetylactis to acidic $\mathrm{pH}$. (C) Inra/Elsevier, Paris.
\end{abstract}

Lactococcus lactis subsp. lactis biovar diacetylactis / citrate transport / regulation of gene expression / lactic acid bacteria / acidic stress

Résumé - Régulation de l'expression du système de transport du citrate chez Lactococcus lactis subsp. lactis biovar diacetylactis. Le métabolisme du citrate chez certaines bactéries lactiques se traduit par la synthèse de composés d'arôme tels que le diacétyle et l'acétaldéhyde. Ces composés contribuent à l'élaboration de la flaveur de certains aliments issus de la fermentation lactique. Le transport du citrate chez Lactococcus lactis subsp. lactis biovar diacetylactis et Leuconostoc mesenteroides subsp mesenteroides est catalysé par un transporteur secondaire, la citrate perméase P. Cette perméase est essentielle pour l'utilisation du citrate. En son absence le citrate n'est pas métabolisé, bien que toutes les enzymes impliquées dans sa conversion soient présentes au niveau de la cellule. Dans cette revue, nous décrivons l'organisation génétique du plasmide codant pour le transport du citrate chez $L$ diacetylactis, la régulation post-transcriptionnelle de l'opéron citQRP et l'influence du $\mathrm{pH}$ extracellulaire sur la transcription du gène citP. Par ailleurs, l'étude du transport du citrate et du cométabolisme citrate-glucose a révélé un nouveau mécanisme moléculaire permettant une meilleure adaptation de $L$. diacetylactis à des $\mathrm{pH}$ acides. (c) Inra/Elsevier, Paris.

Lactococcus lactis subsp. lactis biovar diacetylactis / transport du citrate/ génétique/ bactérie lactique/ stress acide

* Correspondence and reprints 


\section{INTRODUCTION}

Citrate is present in milk and is cometabolized together with sugars by many strains of lactic acid bacteria (LAB) including Lactococcus lactis subsp. lactis biovar diacetylactis [2]. The breakdown of citrate results in the production of carbon dioxide responsible for the texture of some cheeses and, for the flavour compound diacety, essential in dairy products such as butter, buttermilk and cottage cheese. Therefore, there is a strong need to control the production of diacetyl in the dairy industry. This can only be achieved by a complete understanding of the mechanisms involved in citrate utilization by $\mathrm{LAB}$. This process is determined by the presence of intracellular enzymes responsible for its metabolism (reviewed in [5]) and, of a membrane bound protein that catalyses the uptake of this compound by the cells. Thus, the transport of citrate limits the rate of citrate metabolization and may modify the bioconversion yield of citrate into aroma compounds. This uptake is catalyzed by the citrate permease P (CitP) encoded by the plasmidic citP gene in L. diacetylactis [3] and Leuconostoc [13]. Here, we will review the actual knowledge concerning the citrate transport in LAB with special emphasis on the molecular basis of this process. Moreover, we will report our recent results concerning to induced expression of $L$. diacetylactis citP by acidification of the growth medium. This stress response results in an increase of citrate transport, which leads to a more efficient glucose utilization with a consequent growth advantage for lactococci at acidic pHs.

\section{GENETIC ORGANIZATION OF THE PLASMID ENCODING THE CITRATE TRANSPORT SYSTEM OF L. DIACETYLACTIS}

The lactococcal citP gene is located in an $8 \mathrm{~kb}$ plasmid called pCIT264 [10] (figure 1), whereas its counterpart from Leuconostoc [15] is harboured by at least

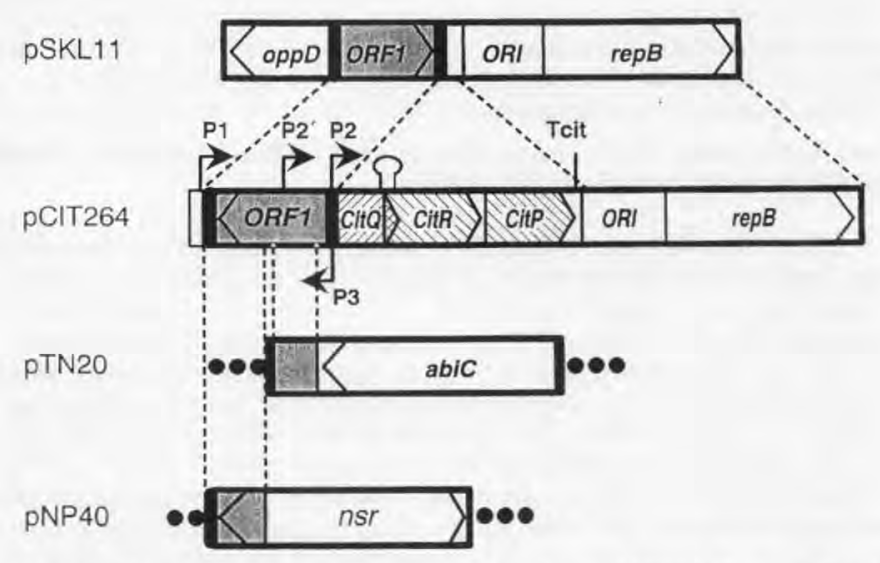

Figure 1. Comparison of lactococcal plasmids carrying regions of IS982. See text for details. P1, $\mathrm{P} 2, \mathrm{P} 2$ ', cit $Q R P$ transcriptional promoters; $\mathrm{T}$ cit, transcriptional terminator for citQRP; $\mathrm{P}$, promoter for ORF1; regions of IS982, shaded boxes; 17 -mer inverted repeats flanking IS982, black boxes.

Figure 1. Comparaison des plasmides de lactocoques portant des régions de IS982. Voir les détails dans le texte. $\mathrm{P} 1, \mathrm{P} 2, \mathrm{P} 2$, promoteurs de transcription de cit $Q R P$; Tcit, terminateur de transcription pour citQRP ; $\mathrm{P} 3$, promoteur pour l'ORF1 ; régions d'IS982, boîtes ombrées ; régions inversées répétées (17-mer) encadrant IS982, boîtes noires. 
two large plasmids $[7,13]$. The two citP genes have $99 \%$ identity. However, the genetic structure and regulation of these two citrate transport systems seem to be different. The lactococcal citP is preceded by two partially overlapping genes (cit $Q$ and cit $R$ ), and together these three genes constitute the citQRP operon [8] In Leuconostoc, the existence of a cit operon and its transcription have not been investigated, but determination of the DNA sequence located upstream and adjacent to cit $P$ revealed that the integrity of $c i t R$ is disrupted by several mutations [15]. Moreover, in this system the levels of CitP seem to increase when citrate is present in the growth medium [14], whereas in $L$. diacetylactis this compound does not influence either transcription or CitP synthesis [10]. In L. diacetylactis, transcription of the citQRP operon yields a 2900 nt cit transcript. The synthesis of this mRNA1 is driven from the $\mathrm{P} 1$ promoter located $1 \mathrm{~kb}$ upstream of citQ, and the transcript terminates at a $\rho$-independent terminator located next to the 3 -end of citP [8], (figure 1). The long leader untranslated region present in mRNA1 contains the insertion sequence-like element IS982, which is flanked by two $17 \mathrm{nt}$ identical inverted repeats $[11,16]$. These sequences bracket the ORF1 located in opposite orientation to citP (see figure I). This ORF1 is homologous to two overlapping ORFs of a putative IS element located upstream of the $g \lg C$ gene from Bacillus stearothermophilus [8].

Plasmid pCIT264 seems to have derived from a parental $\mathrm{Cit}^{+}$plasmid by the occurrence of a transpositional event during evolution. The introduction of the IS982 generated two new transcriptional promoters $\mathrm{P} 3$ and $\mathrm{P} 2$. P3 supports expression of ORF1 of unknown function [11], and $\mathrm{P} 2$ increases expression of the citQRP operon in L. diacetylactis [9] . Moreover, IS 982 contains $\mathrm{P}^{\prime}$, which is the only functional promoter for expression of $c i t P$ in
Escherichia coli. Thus, the presence of IS982 in pCIT264 activates the operon in the heterologous host. The IS 982 has a wide distribution among the lactococcal genome. Several copies of this element were detected in the chromosome of various lactococcal strains $[11,16]$. Analysis of the NBRF data bank reveals that pTN20 and pNP40 plasmids contain regions of the IS982 (figure 1). A fragment of $236 \mathrm{nt}$ of the element has $99 \%$ identity with a region of pTN20 located next to the 3 -end of the abortive infection phage gene $(a b i C)$, and upstream of the nisin resistance gene (nsr) of pNP40 are present $190 \mathrm{nt}$ out of 192 of the IS 982 left region. In addition, one copy of the entire IS982 is located between the origin of replication (ori) and the oligopeptide transport system (opp) of plasmid pSKL11 [16]. Interestingly, pCIT264 and pSKL11 replication regions are highly homologous, and belong to the pWV02 family which replicates via $\theta$ mode [6]. Thus, the conspicuous genetic fluidity, which is characteristic of $\mathrm{LAB}$ seems to be responsible for the actual genetic organization of the plasmid involved in citrate transport in L. diacetylactis.

\section{POSTTRANSCRIPTIONAL REGULATION OF EXPRESSION OF THE CITQRP OPERON}

The cit $P$ gene and its product $\mathrm{CitP}$ are the only requirements for the citrate transport system in $L$. diacetylactis [10]. The cit $Q$ and cit $R$ genes seem to play a role in regulation of levels of CitP in the cell. The central region of cit $Q$ and the 5 -end of $c i t R$ are included in a complex secondary structure, and the cit mRNA1 is processed at this location in L. diacetylactis [8]. The identification of the $5^{\prime}$-end of the processed species showed that the endonucleolytic cleavage should interfere with translation of cit $Q$ and citR [4]. This processing also occurs in E. coli, and its ana- 
lysis in RNase mutants of this host indicates that the endoribonuclease RNase III is involved in this process [4]. Utilization of an E. coli in vitro transcription-translation system has allowed to identify the products of translation of cit $Q$ and citR. The molecular mass of the products indicates that translation of both genes start at the first AUG of citQ, which is located upstream of the secondary structure. Provided that $c i t Q$ and $c i t R$ overlap but they are respectively in 0 and -1 frame, the synthesis of the CitQ-CitR polypeptide should be due to a frameshifting event catalyzed by the ribosomes. Thus, the interplay of translation of cit $Q$ and processing of the cit mRNA seems to control the expression of these genes. Moreover, these processes are connected with the expression of citP, because interruption of cit $Q$ at the major processing site results in an enhancement of CitP synthesis. At the present stage the nature of this complex regulation is not fully understood and further research should be developed on this subject.

\section{ACTIVATION OF THE CITRATE TRANSPORT SYSTEM AT ACIDIC PH}

The citrate uptake is influenced by the external $\mathrm{pH}$ in lactococci. CitP shows optimal activity within a narrow $\mathrm{pH}$ range of 4.5-5.5 [12], and the specific rates of citrate utilization by growing cells drastically increase upon decrease of $\mathrm{pH}$ from 6.5 to $5.5[1,5]$. Moreover, both acidification of the medium and shift to acidic $\mathrm{pH}$ result in induction of transcription of the citQRP operon as well as enhancement of the citrate transport activity in $L$. diacetylactis (García-Quintáns, personal communication). In this report, influence of $\mathrm{pH}$ of the medium in growth and metabolism of CRL264/pCIT264 (Cit ${ }^{+}$) and CRL30 (isogeneic strain cured of pCIT264) (Cit ${ }^{-}$) was investigated (figure 2). At neutral $\mathrm{pH}$, both strains utilize efficiently glu- cose as energy source, and release of lactate was accompanied by acidification of the medium. In contrast, at pH 4.5 glucose supports poor growth of both strains. The final cellular mass was 4 -fold lower than that at $\mathrm{pH} 7.0$. The substitution of glucose by citrate impaired the growth of both strains at neutral $\mathrm{pH}$. These results were expected since citrate does not support growth at neutral $\mathrm{pH}$ [5]. CRL264, but not CRL30, consumed $40 \%$ of citrate at $\mathrm{pH} 4.5$, and this consumption was accompanied by alkalinisation of the medium. This citrate metabolism allowed cellular growth at the same rate and final absorbance than that supported by glucose at acidic $\mathrm{pH}$. However, it only provided to CRL264 slight growth advantage as compared with CRL 30 . In contrast, the utilization of citrate by CRL264 in the presence of glucose had a drastical influence. At neutral $\mathrm{pH}$, this strain cometabolizes very efficiently glucose and citrate. At acidic pH, CRL264 reached a final absorbance as high as that obtained in M17G at $\mathrm{pH} 7.0$, and 4-fold higher than that displayed by CRL 30 at acidic $\mathrm{pH}$. Moreover, in these conditions the growth of CRL264 results in alkalinization of the medium. This effect should be ascribable to citrate transport inside the cells, since it was not detected with CRL30. Furthermore, the slope of the $\mathrm{pH}$ curve correlates with consumption of citrate up to $7.5 \mathrm{~h}$ of incubation. When the $\mathrm{pH}$ reached a value above 4.75 , the rate of decay of citrate dramatically increased indicating that a maximum transport activity was achieved. This behaviour was accompanied by a diauxic growth curve like, and was not correlated with the production of lactate. When the $\mathrm{pH}$ was over 5.0 a very efficient consumption of glucose started to take place, not ascribable to the increase in cellular mass. This utilization of sugar correlated with lactate production, whose secretion presumably provoked the observed acidification of the medium at longer incubation times. It has been reported that 


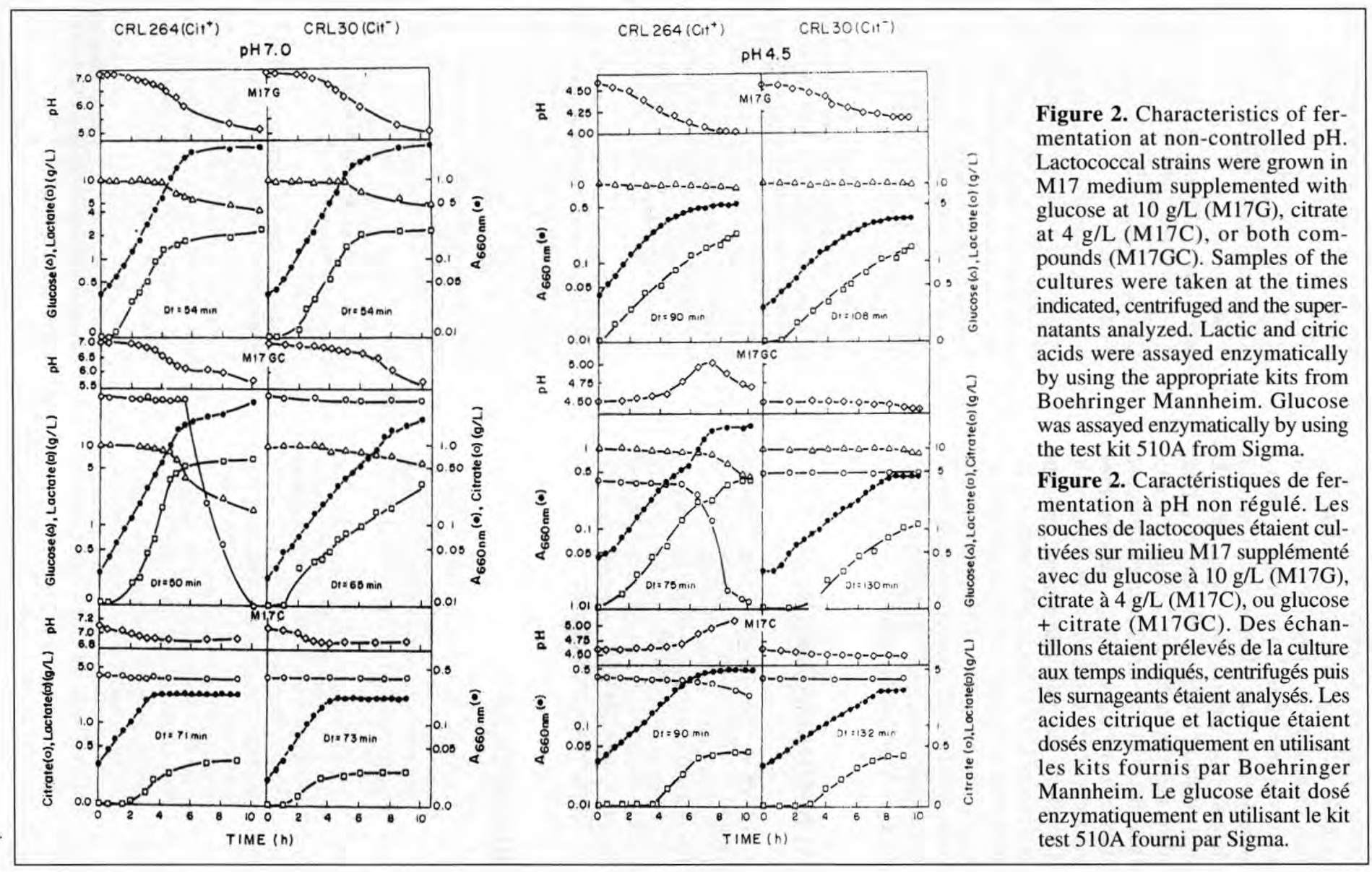


citrate-glucose cometabolism provides growth advantage to $L$. mesenteroides and that utilization of citrate alkalinises the external medium [14]. Here, we have observed that this alkalinisation results in an enhancement of glucose metabolism and strongly increases the rate of citrate utilization in lactococci. Thus, it seems that the interplay of citrate and glucose metabolisms achieved by $L$. diacetylactis counteracts the acidic stress during growth. Therefore, the induction of synthesis and activity of CitP at acidic pHs seems to be designed to support an efficient citratesugar cometabolism. This phenomenon could provide to $L$. diacetylactis a selective advantage, which should enlarge its survival in fermented products.

\section{ACKNOWLEDGMENTS}

This work was supported by the Commission of the European Communities grant CI1 ${ }^{*}$ CT94-0016. Research at the CIB and PROMUBIE were supported, respectively, by CICYT grants BIO95-0794 and BIO97-0347. and Comunidad de Madrid grant 06G/002/96. Research at PROMUBIE by grants of CONICYT and Fundacion Antorcha.

\section{REFERENCES}

[1] Cachon R., Daniel S., Diviès C., Protondependent kinetics of citrate uptake in growing cells of Lactococcus lactis sups. lactis bv. diacetylactis, FEMS Microbiol. Lett. 131 (1995) 319-323.

[2] Cocaign-Bousquet M., Garrigues C., Loubiere P., Lindley N.D., Physiology metabolism of pyruvate in Lactococcus lactis, Antonie van Leeuwenhoek 70 (1996) 253-267.

[3] David S., van der Rest M.E., Driessen A.J.M., Simmons G., de Vos W.M., Nucleotide sequence and expression in Escherichia coli of the Lactococcus lactis citrate permease gene, J. Bacteriol. 172 (1990) 5789-5794.

[4] Drider D., Santos J.M., Arraiano C.M., López P., RNA processing is involved in the posttranscriptional control of citQRP from Lactococcus lactis, Mol. Gen. Genet (1998) in press.
[5] Hugenholtz J., Citrate metabolism in lactic acid bacteria, FEMS Microbiol. Rev. 12 (1993) 165-178.

[6] Kiewiet R., Bron S., de Jonge K., Venema G., Seegers J., Theta replication of the lactococcal plasmid pWV02, Mol. Microbiol 10 (1993) 319-327.

[7] Lin J., Schmitt P., Diviès C., Characterization of a citrate-negative mutant of Leuconostoc ssp. mesenteroides: metabolic and plasmidic properties, Appl. Microbiol. Biotechnol. 34 (1991) 628-631.

[8] López de Felipe F., Magni C., de Mendoza D., López P., Citrate utilization gene cluster of the Lactococcus lactis biovar diacetylactis: organization and regulation of expression, Mol. Gen. Genet. 246 (1995) 590-599.

[9] López de Felipe F., Magni C., de Mendoza D., López P., Transcriptional activation of the citrate permease P., gene of Lactococcus lactis biovar diacetylactis, Mol. Gen. Genet. 250 (1996) 428-436.

[10] Magni C., López de Felipe F., Sesma F., López P., de Mendoza D., Citrate transport in Lactococcus lactis subsp. lactis biovar diacetylactis, Expression of the citrate permease $\mathrm{P}$, FEMS Microbiol. Lett. 118 (1994) 75-82.

[11] Magni C., López de Felipe F., López P., de Mendoza D., Characterization of an insertion sequence-like element identified in plasmid pCIT264 from Lactococcus lactis biovar diacetylactis, FEMS Microbiol. Lett. 136 (1996) 289-295.

[12] Magni C., López P., de Mendoza D., The properties of citrate transport catalyzed by CitP of Lactococcus lactis biovar diacetylactis, FEMS Microbiol. Lett. 142 (1996) 265-269.

[13] Marty-Teysset C., Lolkema J.S., Schmitt P., Diviès C., Konings W.N., Membrane potential-generating transport of citrate and malate catalyzed by CitP of Leuconostoc mesenteroides, J. Biol. Chem. 270 (1995) 25370-25376.

[14] Marty-Teysset C., Lolkema J.S., Schmitt P. Diviès C., Konings W.N., Proton motive force generation by citrolactic fermentation in Leuconostoc mesenteroides, J. Bacteriol. 178 (1996) 2178-2185.

[15] Vaughan E.E., David S., Harrington A., Daily C., Fitzgerald C.F., de Vos W.M., Characterization of plasmid-encoded citrate permease (citP) genes from Leuconosioc species reveals high sequence conservation with the Lactococcus lactis citP gene, Appl. Environ. Microbiol. 61 (1995) 3172-3176.

[16] Yu W., Mierau I., Mars A., Johnson E., Dunny G., McKay L.L., A novel insertion sequence-like element IS982 in lactococci, Plasmid 33 (1995) 218-225. 